\title{
U⿱宀⿻三丨口
}

\section{Exploring the needs of socially excluded young men}

Rondon-Sulbaran, J., Campbell, J., Galway, K., \& Leavey, G. (2012). Exploring the needs of socially excluded young men. Children \& Society, 28, 104-115. https://doi.org/10.1111/j.1099-0860.2012.00457.x

Link to publication record in Ulster University Research Portal

\section{Published in:}

Children \& Society

\section{Publication Status:}

Published (in print/issue): 01/01/2012

DOI:

10.1111/j.1099-0860.2012.00457.x

\section{Document Version}

Publisher's PDF, also known as Version of record

\section{General rights}

Copyright for the publications made accessible via Ulster University's Research Portal is retained by the author(s) and / or other copyright owners and it is a condition of accessing these publications that users recognise and abide by the legal requirements associated with these rights.

\section{Take down policy}

The Research Portal is Ulster University's institutional repository that provides access to Ulster's research outputs. Every effort has been made to ensure that content in the Research Portal does not infringe any person's rights, or applicable UK laws. If you discover content in the Research Portal that you believe breaches copyright or violates any law, please contact pure-support@ulster.ac.uk. 


\section{Meeting the Needs of Vulnerable Young Men: A Study of Service Provider Views}

Jim Campbell*

School of Sociology, Social Policy and Social Work, Queens University Belfast, UK

Janeet Rondon, Karen Galway and Gerry Leavey

Northern Ireland Association for Mental Health, Northern Ireland, UK

This article uses a qualitative approach to elicit the views of 31 professionals who provide services to vulnerable young men. The findings reveal six key themes following focus group interviews: (i) the importance of masculinity in explaining problematic behaviour; (ii) the misuse of alcohol and drugs; (iii) alienation and social isolation; (iv) concerns about suicide and self-harm; $(v)$ the quality of existing services; and (vi) recommendations for changes to services. Service providers generally acknowledged the social context in explaining these behaviours and argued for enhanced services and a more developed skills base in working with vulnerable young men. (C) 2011 The Author(s). Children \& Society (C) 2011 National Children's Bureau and Blackwell Publishing Limited.

Keywords: Northern Ireland, service providers, vulnerability, young men.

\section{Introduction}

Policy-makers, professionals and the wider public have become increasingly concerned about the complex social, health and educational problems faced by young men; such views are often couched in discourses about risk and vulnerability (Joe and Niedermeier, 2008; McCloskey and Lichter, 2003). A number of factors may lie behind such behaviours. Greater numbers of children and young people are being diagnosed with emotional and psychiatric disorders (Green and others, 2005) and polydrug use is common (Kapusta and others, 2006), often leading to co-morbid mental health problems (Fergusson and others, 2003). These behaviours can lead to higher risk of involvement in criminal justice systems (Richardson and Budd, 2003). Young men often encounter a range of other forms of social problems associated with poor educational outcomes and exclusion from the labour market (Furlong and Cartmel, 2004; Hammer, 2003). Uncertainty about perceptions of gender and masculinity amongst young men (Benyon, 2002; Frosh and others, 2003) are often expressed in risky, violent behaviours. Unfortunately many young men are often reluctant to use health, social care and educational services for a variety of reasons, including feelings of embarrassment, stigma and distrust of professionals (Armstrong and others, 2000; Biddle and others, 2006; Richardson and Rabiee, 2001).

\section{Young men in Northern Ireland}

The following study explored these types of problems through the eyes of professionals working in Northern Ireland (NI), a jurisdiction within the UK. It is worth stating that there are considerable socioeconomic and political contextual differences. Chief among these are 
the health and social problems that have emerged following almost 40 years of civil conflict (OFMDFM, 2009). Secondly, compared to the rest of the UK, NI has higher levels of long term unemployment and disability needs, resulting in more dependence on state benefits. It remains an ethnically homogenous society, however, a considerable proportion of the new migrant communities have arrived in the last decade (http://www.nisra.gov.uk). Some groups of young people are in particular need. Only 37 per cent of young people in deprived areas leave school with five or more GCSEs, compared to a societal average of 61 per cent (OFMDFM, 2008), with a number of studies finding associations between educational disadvantage and drug use (McCrystal and others, 2007). There are a number of debates about how 40 years of political conflict have affected the lives of young people (McAlister and others, 2009). Some researchers have argued that most children and young people may not been adversely affected, psychologically, than might be expected (Lloyd and others, 2008). It may be that young people exhibit a mix of responses, sometimes reinforcing the sectarianism of divided communities, whilst at other times demonstrating resilience and resistance (Leonard, 2010). McAloney and others (2009) hypothesize that the concept of intergenerational narratives may subtly, and adversely, affect the lives of young people. In these circumstances, it is hardly surprising that young people will be exposed to other problematic behaviours such as criminal activity, antisocial activity, substance misuse and aggression (O'Reilly and Stevenson, 2003). In a study of socially disadvantaged young men who were both victims and perpetrators of violence, Reilly and others (2004) found that the respondents were able to distinguish costs and benefits associated with how they viewed their masculine identities. It is apparent that there is a differentiated, gendered experience amongst young people, with a tendency for young women, rather than young men, to traverse sectarian spaces and boundaries (McGrellis, 2005). Hargie and others (2001) suggest that the conflict has altered established patterns of adolescent self-disclosure; young women were more likely to talk about their problems than young men. Perhaps of greatest concern to policy-makers has been a consistent rise in suicide and self-harm amongst young men in NI, at a time when large scale conflict is diminishing. Between 2001 and 2006 suicide rates have increased from 9.4 (per 100 000) to 11.4 (a 21\% increase), with rural areas experiencing a greater increase from 7.8 to 10.4 (30\%) over the same period (Tomlinson, 2007). The government has responded to these concerns by targeting a 15 per cent reduction in suicide rates amongst young people. (DHSSPS, 2006b)

Although there is growing awareness of the problems and needs of young men in NI, comparatively little research has examined the nature of service provision for this group. There are well-established systems of educational and community-based support for young people, but these can be fragmented, unevenly delivered and often segregated along the lines of religion. Harland and Morgan (2003), in their review of youth work services in NI, describe a traditional system that has not kept pace with social and economic changes that affect the lives of young men. They argue for more creative interventions that challenge popular stereotypes of masculinity and risk. McElearney and others (2007) recommend a more robust schools' counselling service to meet the high levels of need found amongst some groups of young people. The government has recognized the urgency for enhanced Child and Adolescent Mental Health Services (Davren, 2007; DHSSPS, 2006a). In a more positive vein, health promotion policies have been used to raise awareness and reducing stigma around mental health problems in schools, youth work and local communities (Department of Health Social Services and Public Safety, 2006b:28). For example, a local initiative developed a campaign to enable young men to seek help when feeling vulnerable (Teehan and others, 2006). 


\section{Methodology}

\section{Study aim and objectives}

The study aimed to explore service providers' views of the social, educational and health problems faced by vulnerable young men living in the southern area of NI. This study was primarily qualitative in nature, using focus groups to gather data (Hennink and Diamond, 1999).

\section{Sampling}

The research area comprised five, local government districts (LGDs) with a population of over 300000 people, of whom 32 per cent are aged below 20 years. Most of the population lives in socially deprived rural areas - three out of the five LGDs in this area are ranked among the top 10 most deprived districts in NI (NISRA, 2001, 2005). Changes in the labour market have led to job shortages in the local economy as well as an influx of migrant workers, particularly from Eastern Europe. This change in population demographics has brought to the surface an increasing problem of racism adding to the existing and ongoing sectarian tensions prevailing in NI (South Tyrone Empowerment Programme, 2006).

A mapping exercise was carried out to establish the range of service providers in the area who were directly working with young men aged 14-19 and deemed to be at risk and vulnerable across a range of health, social care and educational factors. Using snowballing techniques, 42 agencies were identified to be providing services to vulnerable young men, 18 of these agencies agreed to participate in the study. The researchers disaggregated these agencies into four types - two community based groups, a statutory health and social services group and an educational group. The projects varied according to the overall remit of the agency (health, social care, youth work) and type of service (statutory, voluntary or community). In total, 31 members of staff ( 20 women and $11 \mathrm{men}$ ) participated in the study. They were generally very experienced, ranging from directors, managers and project workers. Female service providers tended to be employed in statutory agencies (social care, education) whereas their male counterparts were more likely to be employed in the voluntary and community sectors (for example as youth and community workers). These variations tended to reflect the gendered make up of such professional groupings. As in other parts of NI, services tended to be religiously segregated (Pinkerton and Campbell, 2002). Only one of the service providers, a voluntary sector organization, had a specific remit to deliver services to minority ethnic communities.

\section{Instruments}

A topic guide was constructed by the research team, advised by steering group of stakeholders. It included a range of some closed, but predominantly open questions on: (i) background information on respondents; (ii) perceptions and assessment of the emotional and social difficulties faced by young men; (iii) the ways in which services attempt to address these; (iv) barriers to service provision; and (v) areas for improvement.

\section{Data collection and analysis}

Five focus groups were carried out with service providers and two individual interviews took place with service providers who were not available for the focus group interviews. 
Interviews were audio-recorded with the permission of the participants. The researchers also took occasional notes to aid memory for the analysis of data. The interviews were transcribed and then audio-checked by the researchers for discrepancies and mistakes. They were then entered into a software package for qualitative analysis (ATLAS-ti 4.2 (London: Scolari, Sage Publications)) which enables data management and retrieval. The data were analysed through thematic analysis generating codes which were categorized into key themes (Glaser and Strauss, 1967). The data, then, were scrutinized separately by researchers for internal reliability (Lecompte and Goetz, 1982). Competing and complementary themes were distinguished allowing the researchers to arrive at the six key themes described in the findings below.

\section{Ethical issues}

Ethical approval for the study was granted by the Northern Ireland Office Research Ethics Committee (NIR03).

\section{Study limitations}

Although the researchers spent some time mapping the range of service providers it was not possible to obtain respondents from the full spectrum of such services in the area. This was a qualitative study, so the findings cannot be extrapolated to the total population of professionals working in this field.

\section{Findings}

Six strong themes emerged from the analysis of the data: (i) the importance of masculinity in explaining problematic behaviour; (ii) the misuse of alcohol and drugs; (iii) alienation and social isolation; (iv) concerns about suicide and self-harm; (v) the quality of services; and (vi) recommendations for changes to services. These themes will now be summarized with illustrative quotes, and identifiers used to explain the background of the respondent: ORG (Organic), SAS (Statutory Adolescent Services) and EDUC (Education). Two focus groups of CBAS (Community Based Adolescent Services) were held, these are denoted as No. 1 or 2 beside the respondent. Following this, and separated with a 'hyphen', the letters $\mathrm{M}$ and $\mathrm{F}$ indicate gender (male or female).

\section{Masculinity and social problems}

Across all four types of service provision respondents associated a range of problematic behaviours (including the misuse of alcohol, involvement in violence and a reticence to express feelings) with young mens' perceptions of their masculinity. The repeating, internalized expressions of masculinity played out by the young men were consistently recognized:

In terms of how young men see themselves ... if I could use the word macho. (CBAS2-M1)

It's that macho image with boys ... It's not even that they have to have the macho image to impress the boys in the class, but they have to have the macho image to impress the girls. (EDUC-F3)

Several workers offered explanations about how this notion of masculinity often closed down opportunities for young men to express hidden feelings, often because of expectations of role: 
I think they [young men] are reluctant to talk generally for a number of reasons ... Part of it is a masculinity macho thing and if they've got problems they should be able to deal with it themselves without having to seek help from anyone else. (ORG-M3)

Because it's a sign of weakness that they would actually say that they're feeling something ... especially if there is a father figure at home: 'My father's a big strong man. I can't ... I'm a weak boy. I want to be like my father.' And that can be very difficult for them as well - very much so. (SAS-F1)

Later in the findings service providers suggest ways in which interventions can be adjusted to engage with these, often problematic, perceptions of masculinity. In particular, many service providers recognized the need for single gender approaches, underpinned by a skills and values base that can be used to encourage young men more readily to seek help.

\section{Alcohol and drugs}

A second strong theme was a concern about the excessive use of drugs and alcohol by young men. A number of respondents acknowledged that there were normative aspects to these behaviours, involving rites of passage and peer group pressure:

... for those young men who don't have problems, there are lots of facilities ... until they get to maybe a certain age group where the peer influence is more a pull on them than any sort of facilities that are available within the area and the pull for drink and drugs ... Ghastly! (EDUC-F6)

... doing drugs and drinking alcohol is the norm for some young people; that is their learned behaviour, that is their culture. (CBAS1-F3)

Interestingly the workers often sought to understand these behaviours less in terms of agency and individual choice, but in the context of social causation, including role stress, social isolation and poorly designed social and leisure facilities:

... the alcohol and drugs can be the young person's way of coping with suppressing the stresses and traumas and everything else that they have ... (CBAS1-F2)

... two of the things a lot of young men do when they get really frustrated or really angry or just feel like they're going to lose it, is they turn to either alcohol or drugs ... The ones that go for the alcohol they then start a riot in the streets. It might be different somewhere else. (ORG-M2)

\section{Alienation and social isolation}

Young men were frequently referred to the service providers because of criminogenic behaviours that followed excessive drinking and use of drugs; this often led to broken social networks and disconnection with their communities:

... you had this particular community ... they were tortured by young people drinking in the area and annoying elderly people. (CBAS-M1)

There's a lack of trust, particularly from the adult communities, about what young men's motives are and what they're doing. Young men are demonised by the communities. (ORG-M1) 
I can think of a community very close to here where young people are completely running amok and there's no relationship between them, no positive influences in that community between the adults and young people. (EDUC-M1)

As a result, unfair generalizations were sometimes made about young men. Such stereotypical views tended to be eschewed by service providers.

In past generations young men had got a clear life choice as such, which was potentially going to work on the farm maybe, potentially maybe going to work in construction sites. There was a clear thing for them there. But now, ... there is a confusion. (CBAS-M1)

There's a general sense of belonging or not belonging to anything and that is across the board, regardless of what the social background is ... it is very much about having a sense of belonging and feeling part of something or even having something in the future. (CBAS1-F3)

The professionals occasionally alluded to issues that were related to the conflict in NI. For example there were,

... paramilitary influences and things like that created problems for [the young men]. (CABS1-M1)

This sometimes occurred when paramilitaries 'policed' areas where young men had been accused of crime and disruptive behaviours that affected the lives of the wider community. Such 'policing' often has disastrous consequences for young men who are subject to 'punishment beatings' and intimidation.

Young men often appeared to internalize these identities:

... The stereotypes of bandits ... was imposed on us and that's what most of the young men feel and so growing up they've seen that as one of their identities, whether they liked it or not. (ORG-M2)

As the traditional social frameworks of work and family have been disrupted and changed, it appears that young men were finding it difficult to understand changing social roles and relationships:

Many [young men] are struggling with new roles and stereotypes and contradictions and I suppose parents and the whole generational thing and that in itself must be a struggle in terms of who are you in this new world, which on the one hand is very liberated and very lovely and materialistic and on the other hand is extremely punitive. (SAS-F2)

Communities aren't there the same and young men are feeling this. They haven't got grannies, they haven't got granddads, they haven't got fathers, they haven't, some, got mothers. They haven't got close connections or bondings there. (ORG-F5)

\section{Suicide and self-harm}

Respondents were acutely aware of concerns about risk of suicide and self-harm for the young men in their care and they identified factors that appeared to increase such risks. For example, one service provider felt that changing religious practices and more secular approaches to moral judgment made suicide more likely: 
I think the Church too lifted the whole element of stigma around suicide and in a way it seems maybe it made suicide that wee bit easier, that there wasn't this stigma around taking your own life. (CABS1-M1)

The shifting patterns of family life and lack of appropriate role models may leave young men with fewer confidents at times of stress:

I suppose you start to realise that maybe the break-up of a marriage or maybe a child from a single parent family that's missing a father figure ... and no matter how young the child is, it still has a traumatic impact on them. So growing up and living with that ... I'm not saying it applies to every single person and it applies in every single case but I suppose it can be a contributing factor [to suicide] as well along with alcohol. (SAS-F1)

Some respondents felt that the pressures caused by social and economic demands and expectations tended to undermine young mens' self-belief and capacity to cope:

... they've got this idea of what they should be achieving ... and the media is telling them, 'At this age you have this and you have that and you've got this.' And maybe they're working in [a supermarket] in the checkout and they know they're not going to get that. (CBAS1-F2)

I mean the economic climate for a young person. When we're talking about they'd have the correlation between disaffection and crime and aspiration, I mean the word I would use is 'chronic'. (CBAS2-M1)

\section{Services for young men}

Respondents were asked to comment upon the quality of services for young men, this question generated a number of responses about a wide range of issues. Service providers acknowledged the way in which deprivation and social isolation created lifestyle problems for young men:

There are very little things that don't cost much. Simple things to cheer you up are expensive. Even going to the swimming pool can be expensive. (SAS-M2)

Now, if you take a young person in this area that's trying to get to any of these services themselves, maybe by bus, there is no direct bus to [the cities] ... in actual fact, most of the service providers don't even come out here. (ORG-M2)

I think there is a level of social deprivation and I think there has been a lack of investment for a number of years in social amenities. (ORG-M3)

In addition, traditional services were viewed to be inflexible or inadequately structured to meet the needs of vulnerable young men, particularly in terms of educational opportunities:

... it's usually when they [young men] start getting settled down into secondary school and they realise: 'No. I'm not going to be that academic person. What am I going to be?' And if the options are quite limited, there has to be something else there. (EDUC-F5) 
Do teachers, do adults realise, even from a personal appearance and self-esteem [point of view], that the boys equally need to go high on that agenda? And I'm not talking about any great health programme that is going to be so radical but just an awareness. (SAS-F2)

There were concerns that, too often, services were piecemeal in their nature and linkages across complex systems were weak:

... funding is a massive issue, particularly for voluntary organisations. (ORG-M1)

... we have had to go various directions to try and look for ... we're not really reaching out to those young people who we would describe as marginalised and disadvantaged. (CAB2-M2)

If the funding was readily available to us we'd be always running things and I would say we would have a better uptake in those kinds of things if they were rolling. So I definitely think that would be an issue - definitely. (SAS-F1)

One particular health issue that was raised in some of the focus groups was the inadequacy of provision of Children and Adolescent Mental Health Services. A common criticism was that this service was largely unavailable or hard to access. This was a particular worry for service providers trying to help young men who were particularly at risk of harm and suicide:

Many people are in crisis and at elevated risk of suicide, they don't need a mental health diagnosis. They might never need to get one but they're in crisis right now and the system can't really respond quick enough to the needs of the presenting clients. (CBAS1-F2)

.... the longer they have to wait the more elevated or more seriously affected they [young men] are by the time that they're seen. If they could be seen earlier ... at the point of contact, the intervention can be also less demanding and much more impactful on the individual. (CABS1-F2)

\section{Improving services}

Because of concerns about the inadequacy of service provision, respondents were keen to identify ways in which interventions could be improved. The following extract is representative of the views of a number of practitioners who appealed for more sensitive approaches. In particular, it was argued that those working with young men should develop skills that would more readily engage young men in confidence - building strategies:

... if you can get a man who is a positive role model who they respect, if they can get that first week or two over to make the proper contact and to say to this person man to man or whatever age the young man happens to be: 'Look, I don't have all the answers either. I'm not here to tell you what to do but I'm trying to provide a place if you feel like talking again.' (ORG-M2)

It may also require a rethink about the importance of interventions at earlier periods in the young man's life:

I think we can't start trying to build relationships with our young men at 15 . This has to be done right when they're toddlers ... We think that as we're growing up it's okay and it's at 15 we want to sit down and have a conversation with him and find out who their friends are ... if we're not doing that with young men from a really young age then they're not going to come and talk to you or want to confide in you at 15 . (ORG-F5) 
Many respondents advocated a move away from a victim-blaming approach to a more empowering view about the potential for positive change:

It's about acceptance too ... About integrating into society rather than narrowing away from certain types of behaviour. (CBAS2-M3)

... The most important thing is that trust and respect, that if I'm going into work with anybody, it doesn't matter what gender or what age, they are an equal human being to me. (ORG-M2)

There was also a recognition that a systemic approach was crucial if services were to achieve good outcomes:

So I think the family is a very important part in this ... empowering the parents to maybe advise and work ... help to develop the young people, ... develop resilience. (ORG-M3)

I think that part of the solution to problems is to involve these young people in saying what they want and what they think they need within their particular area. They are part of the problem; so they're also part of the solution. (CABS1-M1)

\section{Discussion}

The findings of this study offer insights into the way a mixed group of professionals understand issues of vulnerability and risk amongst young men, and how services might respond to these complex needs. Most service providers acknowledged the part that perceptions of masculinity and role confusion played in explaining problematic, risky behaviour. When rejected or abandoned by their community and helping agencies, many young men chose, or get drawn into, antisocial behaviours that are often underpinned by destructive "performances of masculinity' (Harland, 2001, p. 293). As a result they tended to be demonized by their communities, prolonging a cycle of social and emotional isolation, heavy alcohol and drug usage, often leading to petty or more serious aggression and violence. A compounding factor may be that young men find formal services, even if well resourced, to be threatening or stigmatizing (Biddle and others, 2006; Richardson and Rabiee, 2001). In addressing these barriers, it becomes possible for professionals to gain the trust of young people and build up empathic and meaningful relationships based on mutual respect (Harland and Morgan, 2003). The findings also confirmed that the struggle to find new ways of communicating with young men was compounded by policy-making mistakes that led to disjointed service provision in this important area of health, social and educational care. Most services offered to young people in need appeared to be reactive in nature or were made overly complex in offering different thresholds or pathways of referral. In addition, there is a need for service providers to be aware of the complexity of youth transitions, particularly in the context of a society facing unusual levels of political conflict. There has been a reduction in political conflict since the signing of the Belfast Agreement in 1998, but many young people continue to experience sectarianism and are subject to, as well as perpetrate, violence (McAlister and others, 2009; Muldoon, 2004), although these experiences are also differentiated by issues of gender, class and locality (Gallagher, 2004). Many of the respondents in this study also questioned the lack of government commitment to initiatives aimed at prevention and promotion; these are often led by poorly resourced voluntary and community sector organizations. All the service provider respondents advocated for new, more sensitive and innovative approaches to meeting needs, particularly through early interventions and in developing ground up approaches to delivering educational, health and social services. 
Although there is some debate about the causes of rising levels of suicide in NI (Tomlinson, 2007), there seems little doubt that young men comprise a particular subpopulation who are exceptionally vulnerable (Teehan and others, 2006). The service providers in this study were understandably concerned about this issue of risk to the young men in their care; explanations were often couched in terms of wider social contexts - family breakup, loss of role and peer group pressures. The reticence of young men, particularly those from low income or marginalized communities (Consedine and others, 2007), to talk about their feelings and emotions was central to professionals' views on risk and suicidal behaviour. Although it is difficult to envisage how individual professionals and agencies could make any substantive changes to generalized patterns of suicidal behaviour, a comprehensive approach to prevention (Department of Health Social Services and Public Safety, 2006b), and more joined up services for adolescents (Davren, 2007; Department of Health Social Services and Public Safety, 2006a) seems necessary.

\section{Conclusion}

This article sought to explore the views of providers of health, social and educational services to vulnerable young men living in rural parts of NI. The types of problems that these young men faced, as described by the service providers, were often those that are highlighted in the research literature. These included social dislocation and alienation from families and communities, risky and sometime violent behaviours, often associated with drug and alcohol use. The service providers were concerned about how competing perceptions of masculinity were viewed, and played out by, the young men, their communities and agencies of control. They also expressed a level of frustration at problems of service planning and provision, yet a continuing optimism about how services could be shaped to meet the complex needs of the young men. The particularity of the Northern Irish conflict sometimes emerged in the responses of service providers, including problems of inter-sectarian violence between groups of young men. It was suggested that some of these factors might explain elevated levels of suicide and suicidal behaviours.

Although the study took place in a mostly rural part of NI, there may be possible lessons for policy-makers and practitioners elsewhere. When young men experience social disadvantage and exclusion, there is a greater chance that masculinity is expressed through risky behaviours; service users and policy-makers therefore should design interventions accordingly (Reilly and others, 2004). Increasing levels of unemployment and social exclusion amongst young people across the UK require a more targeted approach to meeting the needs of marginalized communities in which young men live, urban as well as rural (Popay and others, 2008). Evidence-based, early intervention and health promotion strategies have demonstrated positive outcomes in reducing violence, substance abuse and emotional problems amongst children and young people (Mental Health Foundation, 2009). Crucially, practitioners have to find ways of deconstructing and reframing notions of masculinity (Johnson, 2001). Young men often lack the emotional literacy needed to identify problems and develop positive coping strategies to deal with adversity. In order to know that they need help, young people first of all have to become aware of their own feelings, emotions and reactions, and be encouraged to analyse and discuss these in safe environments, with trusted adults. Helping young people to develop this awareness is an important step towards developing resilience and the capacity for problem solving, ideally before crises occur. 


\section{References}

Armstrong C, Hill M, Secker S. 2000. Young peoples' perception of mental health'. Children and Society 14: 60-72.

Benyon J. 2002. Masculinities and Culture. Open University Press: Buckingham, Philadelphia.

Biddle L, Donovan JL, Gunnell D, Sharp D. 2006. Young adults' perceptions of GPs as a help source for mental distress: a qualitative study. British Journal of General Practice 56: 924-931.

Consedine NS, Sabag-Cohen S, Krivoshekova YS. 2007. Ethnic, gender, and socio-economic differences in young adults' self-disclosure: who discloses what and to whom? Cultural Diversity and Ethnic Minority Psychology 13: 254-263.

Davren M. 2007. Child and adolescent mental health services and the strategic context: the bigger picture. Child Care in Practice 13: 327-338.

Department of Health Social Services and Public Safety. 2006a. A Vision of a Comprehensive Child and Adolescent Mental Health Service. DHSPPS (NI): Belfast.

Department of Health Social Services and Public Safety. 2006b. Protect Life: A Shared Vision. Northern Ireland Suicide Prevention Strategy and Action Plan 2006-2011. DHSSPS (NI): Belfast.

Fergusson DM, Horwood LJ, Swain-Campbell NR. 2003. Cannabis dependence and psychotic symptoms in young people. Psychological Medicine 33: 15-21.

Frosh S, Phoenix A, Pattman R. 2003. The trouble with boys. The Psychologist 16: 84-87.

Furlong A, Cartmel F. 2004. Vulnerable Young Men in Fragile Labour Markets: Employment, Unemployment and the Search for Long-term Security. Joseph Rowntree: York.

Gallagher T. 2004. After the war comes peace? An examination of the impact of the Northern Ireland conflict on young people. Journal of Social Issues 60: 629-642.

Glaser BG, Strauss AL. 1967. The Discovery of Grounded Theory; Strategies for Qualitative Research. Aldane: Chicago.

Green H, McGinnity A, Meltzer H, Ford T, Goodman R. 2005. Mental Health of Children and Young People in Great Britain. Department of Health: London.

Hammer T. 2003. The probability for unemployed young people to re-enter education or employment: a comparative study in six Northern European countries. British Journal of Sociology of Education 24: 209-223.

Hargie OD, Tourish D, Curtis L. 2001. Gender, religion and adolescent patterns of self disclosure in the divided society of Northern Ireland. Adolescence 36: 65-79.

Harland K. 2001. The challenge and potential of developing a more effective youth work curriculum with young men. Child Care in Practice 7(4): 288-300.

Harland K, Morgan S. 2003. Work with young men in Northern Ireland-an advocacy approach. Youth Ct Policy 81: 74-85.

Hennink M, Diamond I. 1999. Using focus groups in social research. In Handbook of the Psychology of Interviewing. Memon A, Bull R (eds.). Wiley \& Sons: London; 113-141.

Joe S, Niedermeier D. 2008. Preventing suicide: a neglected social work research agenda. British Journal of Social Work 38: 507-530.

Johnson D. 2001. Masculinities in rural Australia: gender, culture and environment. Unpublished Ph.D. thesis, University of Western Sydney.

Kapusta ND, Ramskogler K, Hertling I, Schmid R, Dvorak A, Walter H, Lesch OM. 2006. Epidemiology of substance use in a representative sample of 18-year-old males. Alcohol and Alcoholism 41: 188-192.

Lecompte MD, Goetz JP. 1982. Problems of reliability and validity in ethnographic research. Review of Educational Research 52: 31-60.

Leonard M. 2010. Parochial geographies: growing up in divided Belfast'. Childhood 17(3): 329-342. DOI: $10.1177 / 0907568210369216$.

Lloyd K, Cairns E, Doherty C, Ellis K. 2008. Adolescent mental health in Northern Ireland: empirical evidence for the Young Life and Times survey. In Schubotz D, Devine P (eds) Young People in Postconflict Northern Ireland. Lyme Regis: Russell House. 
McAloney K, McCrystal P, Percy A, McCartan C. 2009. Damaged youth: prevalence of community violence exposure and implications for adolscent well-being in post-conflict Northern Ireland. Journal of Community Psychology 37: 635-648.

McAlister S, Scraton P, Haydon D. (2009). Childhood in Transition. Experiencing Marginalisation and Conflict in Northern Ireland. Queen's University Belfast, Save the Children, The Prince's Trust: Belfast

McCloskey L, Lichter EL. 2003. The contribution of marital violence to adolescent aggression across different relationships. Journal of Interpersonal Violence 18: 390-412.

McCrystal P, Percy A, Higgins K. 2007. The cost of drug use in adolescence: young people, money and substance abuse. Drugs: Education Policy and Prevention 14: 19-28.

McElearney A, Adamson G, Shevlin M, Tracey A. 2007. Independent schools counselling: profiling the NSPCC service experience. Child Care in Practice 13: 95-115.

McGrellis S. 2005. Pure and bitter spaces: gender, identity and territory in Northern Irish youth transitions. Gender and Education 17: 515-529.

Mental Health Foundation. 2009. Young People with Mental Health Problems. MHF: London.

Muldoon OT. 2004. Children of the troubles: the impact of political violence in Northern Ireland. Journal of Social Issues 60: 453-468.

NISRA. 2001. Northern Ireland Census 2001. Key Statistics. Northern Ireland Statistics and Research Agency: Belfast.

NISRA. 2005. Report of the Interdepartmental Urban-Rural Definition Group. Statistical Classification and Delineation of Settlements. Northern Ireland Statistics and Research Agency: Belfast.

NISRA. 2011. Available at http://www.nisra.gov.uk [Accessed 22 February 2011].

Office of the First Minister and Deputy First Minister. 2008. Lifetime Opportunities. Government's Anti-poverty and Social Inclusion Strategy for Northern Ireland. OFMDFM, Central Anti-Poverty Unit: Belfast.

Office of the First Minister and Deputy First Minister. 2009. Strategy for Victims and Survivors. OFMDFM: Belfast.

O'Reilly D, Stevenson M. 2003. Mental health in Northern Ireland: have "the troubles" made it worse?. Journal of Epidemiology and Community Health 57: 488-492.

Popay J, Escorel S, Hernandez M, Johnston H, Mathieson J, Rispel L. 2008. Understanding and Tackling Social Exclusion. Final Report to the WHO Commission on Social Determinants of Health from the Social Exclusion Knowledge Network. Lancaster University: UK.

Pinkerton J, Campbell J. 2002. Social work and social justice in Northern Ireland: towards a new occupational space. British Journal of Social Work 32(6): 723-737.

Reilly J, Muldoon OT, Byrne C. 2004. Young men as victims and perpetrators of violence in Northern Ireland: a qualitative analysis. Journal of Social Issues, 60: 469-484.

Richardson A, Budd T. 2003. Alcohol, Crime and Disorder: A Study of Young Adults. Home Office Research Study No. 263. Home Office: London.

Richardson CA, Rabiee F. 2001. A question of access: an exploration of the factors that influence the health of young males aged 15-19 living in Corby and their use of health care services. Health Education Journal 60: 3-16.

South Tyrone Empowerment Programme. 2006. Literature Review. Black and Minority Ethnic Groups, Including Migrant Workers. Southern Investing for Health Partnerships: Armagh.

Teehan B, McNamee D, Donnelly L. 2006. Help-seeking attitudes and behaviours among young people in Northern Ireland. Journal of Public Mental Health 5: 35-41.

Tomlinson M 2007. The Trouble with Suicide. Mental Health, Suicide and the Northern Ireland Conflict: a review of the evidence. School of Sociology, Social Policy and Social Work, Queen's University Belfast: Belfast.

*Correspondence to: Dr. Jim Campbell, Senior Lecturer in the School of Sociology, Social Policy and Social Work, Queens University Belfast, Belfast, UK, Tel.: +44 0289097371. E-mail: jim.campbell@qub.ac.uk

Accepted for publication 12 November 2010 